\title{
Effect of intraarterial papaverine and/or angioplasty on the cerebral veins in patients with vasospasm after subarachnoid hemorrhage due to ruptured intracranial aneurysms
}

\author{
Ayman A. Elsayed, M.D., Christopher J. Moran, M.D., DeWitte T. Cross III, M.D., \\ Colin P. Derdeyn, M.D., Thomas K. Pilgram, Ph.D., James M. Milburn, M.D., \\ RalPh G. DaCey JR., M.D., AND Michael N. Diringer JR., M.D.
}

\author{
Departments of Radiology, Neurological Surgery, and Neurology, Washington University School of \\ Medicine, St. Louis, Missouri
}

\begin{abstract}
Object. The goal in this study was to determine if there was a change in intracranial venous diameters after endovascular treatment of carotid distribution vasospasm caused by subarachnoid hemorrhage.

Methods. The venous diameters were measured in all patients who received intraarterial papaverine and/or balloon angioplasty for treatment of vasospasm during the study period of 3 years. To evaluate the veins of Labbé and Trolard, the straight sinus, and the superior sagittal sinus (SSS), measurements were performed in a blinded manner with the aid of a magnification loupe. Predetermined sites were evaluated on angiograms obtained before and after endovascular treatment. Forty-three treatments in 26 patients were included: 18 patients (33 territories) were treated with intraarterial papaverine alone, four (four territories) were treated with balloon angioplasty alone, and four (six territories) were treated with both papaverine infusion and angioplasty.

The mean measured venous diameters increased significantly after addition of papaverine (10.9\%), and also after combined papaverine and angioplasty (4.2\%). There was no statistically significant increase in the mean venous diameters after angioplasty alone. If the initial intracranial pressure (ICP) was less than $15 \mathrm{~mm} \mathrm{Hg}$ before treatment, the veins showed a greater tendency to dilate than if the initial ICP measurements were greater than $15 \mathrm{~mm} \mathrm{Hg}$. The straight sinus and the SSS increased more in diameter than the veins of Labbé and Trolard. There was no statistically significant correlation between the change in venous diameters with treatment and ICP.

Conclusions. Endovascular treatment produces measurable increases in intracranial venous diameters. However, these changes do not correlate with changes in ICP.
\end{abstract}

\section{KEY WORDS • vasospasm • subarachnoid hemorrhage • cerebral blood flow • cerebral vein • brain}

$\mathrm{B}$ LOOD in the subarachnoid space triggers a pathological process that results in a sustained muscle spasm of the cerebral arteries, leading to decreased CBF. ${ }^{11,36}$ These changes in the intrinsic control of CBF are particularly deleterious because several additional factors may operate to decrease flow after SAH, including decreased CPP attributable to increased ICP, which can be caused by acute hydrocephalus or clot formation. ${ }^{41}$ Neurological deterioration is potentially reversible if adequate blood flow through vasospastic cerebral vessels can be restored before infarction occurs. Endovascular therapy, including balloon angioplasty 1,12,13,19,23,32,43,44 and/or intraarterial papaverine infusion, has been advocated by various authors based on differing hypotheses regarding the pathogenesis of vasospasm. $., 13,16-18,23,26,31,38,40$

Papaverine is an alkaloid of the opium group that indu-

Abbreviations used in this paper: $\mathrm{CBF}=$ cerebral blood flow; $\mathrm{CBV}=$ cerebral blood volume; $\mathrm{CPP}=$ cerebral perfusion pressure; $\mathrm{CSF}=$ cerebrospinal fluid; $\mathrm{ICP}=$ intracranial pressure; $\mathrm{SAH}=$ subarachnoid hemorrhage; SSS = superior sagittal sinus. ces vasodilation of cerebral arteries by inhibiting smoothmuscle contraction. ${ }^{15}$ The successful use of intraarterial papaverine for the treatment of vasospasm has been reported. 2,15,16,19,24,26,29 Even small changes in vessel caliber translate into significant alterations in CBF, because cerebrovascular resistance is theoretically proportional to the fourth power of the vessel radius., ${ }^{4,36}$ Patients who do not respond clinically despite a good angiographic result are of

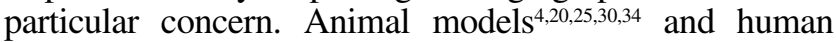
studies $^{27}$ have shown that ICP may increase significantly during papaverine infusion..$^{25,30}$ The effects of angioplasty on arterial size are very evident, but its effects on cerebral hemodynamics have not been thoroughly evaluated. Because venous blood accounts for $60 \%$ of the intracranial blood volume, ${ }^{39}$ assessment of the effect of endovascular therapy on the intracranial venous system may contribute to a greater understanding of cerebral hemodynamics. In this study, the venous diameters were measured before and after endovascular treatment of carotid distribution vasospasm. A correlation between the venous diameter changes and ICP changes was also sought. 


\section{Clinical Material and Methods}

All patients who received intraarterial papaverine therapy and/or balloon angioplasty for treatment of symptomatic vasospasm of the carotid circulation during the study period of 3 years were eligible for inclusion. Symptomatic vasospasm was diagnosed when patients experienced new neurological deficits or a decreased level of consciousness (this diagnosis was made after exclusion of hydrocephalus, cerebral edema, infection, or metabolic disturbances). In all patients vasospasm resulted from SAH secondary to saccular aneurysm rupture. Before undergoing angiography, all patients received maximal medical therapy, which continued after endovascular therapy. Patients whose angiograms were not filmed to include proper venous-phase images were excluded. This resulted in exclusion of 13 treatments in seven patients. Data from treatment of the vertebrobasilar system were not included in this study.

Forty-three treatments in 26 patients were included. Patients were assigned to one of three groups: 18 patients (33 territories) were treated with intraarterial papaverine alone, four (six territories) were treated with both papaverine infusion and angioplasty, and four (four territories) were treated with balloon angioplasty alone. There were 17 women and nine men with a mean age of 56.9 years and a range of 32 to 81 years.

Of the ruptured aneurysms, 12 were located at the anterior communicating artery, five at the posterior communicating artery, four at the middle cerebral bifurcation, one at the ophthalmic segment, one at the internal carotid bifurcation, one at the basilar tip, one at the pericallosal artery, and one at the anterior choroidal artery.

Of the 26 patients, four were classified in Hunt and Hess $^{14}$ Grade I, two in Grade II, 10 in Grade III, and 10 in Grade IV at presentation. One patient was classified in Fisher ${ }^{6}$ Grade 1, six in Grade 2, nine in Grade 3, and 10 in Grade 4.

Papaverine (300 mg) was infused into the cervical internal carotid artery at the C1-2 level over 15 to 60 minutes. The rate of infusion was adjusted according to the change in ICP, which is monitored continuously in all patients receiving endovascular therapy at our institution. The CPP (calculated as the mean arterial pressure - ICP) was maintained at $60 \mathrm{~mm} \mathrm{Hg}$ or higher by slowing the infusion if necessary.

All digital subtraction angiograms were acquired at two frames per second on biplane angiographic equipment (Neurostar; Siemens AG, Munich, Germany) using nonionic contrast material (Optiray 320; Mallinckrodt Medical, St. Louis, MO). We also evaluated the veins on the diagnostic angiograms performed on presentation in 11 patients for comparison of the pre- and posttreatment results. The initial angiograms in the remaining 15 patients were unavailable for review.

Bilateral carotid papaverine infusion was performed in 12 patients during the same session. Venous diameters measured after the first carotid infusion were compared with those obtained after infusion of both sides in these patients.

Measurements were performed in a blinded manner by a single observer. All identifying data were obscured on the films to display only the venous image. The organiza- tion of the films and the selection of measurement positions were performed on a different day from actual measurements. Measurements were made at four predetermined sites on the lateral views of venous-phase angiograms before and after endovascular treatment. These included the midportions of the veins of Trolard and Labbé, the midportion of the straight sinus, and the SSS just above the torcular herophili.

Veins were measured using a magnification loupe graduated to $0.2 \mathrm{~mm}$. The lateral margins of the contrast column were marked on the film by using a sharp soft lead pencil to improve the image when viewing with the loupe. The vessel diameters were recorded to the nearest $0.1 \mathrm{~mm}$. Because digital subtraction angiography was used and there was variability in magnification between angiograms, this was corrected by dividing the measured cranial diameters (lateral projection) into the measured venous diameters to achieve relative values.

Values at presentation were compared with pretreatment values. Similarly, the pretreatment values were compared with the posttreatment values to measure the change with treatment. Differences between treatment groups were examined using independent sample t-tests. Differences in vessel diameters associated with different veins were examined using the analysis of variance method.

Measurement reliability was determined by repeating 27 randomly selected measurements. A line was fitted to the original/repeat points by simple regression. The fit of the line was very good $\left(r^{2}=0.99\right)$, and the $95 \%$ confidence intervals for the slope and intercept included 1 and 0 , respectively, from which we infer that the relationship between the original and repeated measures was a simple one-to-one relationship with very little variability.

A possible correlation between venous diameter change and cerebral circulation time was explored. The cerebral circulation time was defined as the interval between the time when the first image was acquired in which contrast agent was visible above the supraclinoid internal carotid artery and the time when the venous image with the highest concentration of contrast in the parietal cortical veins was obtained. ${ }^{28}$

Arterial diameter changes were measured before and after treatment at 12 predetermined sites chosen to represent proximal, intermediate, and distal arteries as previously reported. ${ }^{29}$ Venous diameter change after treatment was compared with arterial diameter change by calculating the Pearson correlation coefficient.

The ICP measurements before and after treatment were also recorded. The ICP change with treatment was correlated to the venous diameter change. Any statistical correlation between initial ICP measurements $(<15 \mathrm{~mm} \mathrm{Hg}$ compared with $15 \mathrm{~mm} \mathrm{Hg}$ ) and venous diameter change was sought. Also a correlation between initial ICP and ICP change with treatment was examined. Venous diameter changes were also correlated with the patient's Hunt and Hess ${ }^{14}$ and Fisher ${ }^{6}$ grades.

\section{Results}

\section{Venous Diameter Changes}

The mean venous diameters on presentation tended to be smaller than the diameters measured immediately pre- 

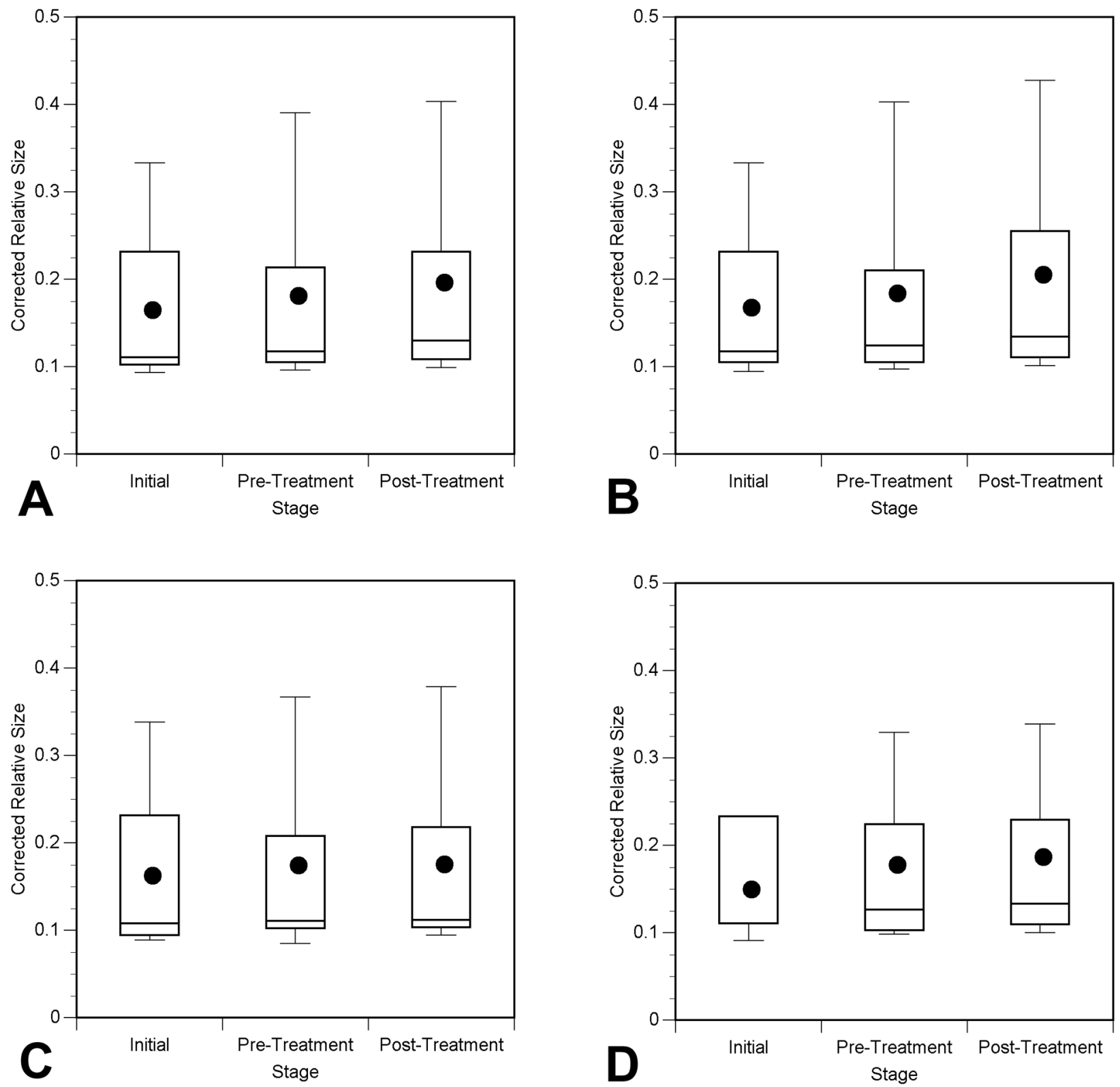

FIG. 1. Quartile plots showing the mean relative venous diameter (black dots), corrected for magnification, on presentation (initial), pretreatment, and posttreatment. The middle bar in each box represents the median; the top and bottom of the box represent the 25th and 75th percentiles, respectively; and the whiskered lines represent the 10th and 90th percentiles. A: All treatments (papaverine, angioplasty, and combined therapies). B: Papaverine alone. C: Angioplasty alone. D: Combined papaverine and angioplasty therapy.

treatment. There was an increase in venous diameters ranging from 4.8 to $11.4 \%$, with a mean of $8.1 \pm 1.7 \%(\mathrm{p}=$ 0.067 , two-tailed paired t-test), with all types of endovascular treatment (Fig. 1A). After administration of papaverine, the mean increase in diameter was $10.9 \pm 2.05 \%$ $(\mathrm{p}<0.0001$, two-tailed paired t-test; Fig. 1B). After angioplasty, the mean increase in diameter was $2.1 \pm 3.5 \%$ $(\mathrm{p}=0.78$, two-tailed paired t-test; Fig. 1C). After combined papaverine and angioplasty treatment, the mean increase in diameter was $4.2 \pm 4.9 \%(\mathrm{p}<0.0001$, twotailed paired t-test; Fig. 1D).
Statistical testing of venous diameter changes by treatment group showed that the change in vessel size after administration of papaverine compared with angioplasty was statistically significant ( $p=0.001$, two-tailed independent samples t-test). The patients who received both papaverine and angioplasty showed a level of change between that of patients who received papaverine alone and those who received angioplasty alone, but this was closer to the change in the angioplasty-only group. However, this was not statistically significant $(p=0.098)$. There were considerable differences in the change in 
venous diameter, depending on the size of the vein (Table 1, Fig. 2).

The veins of Labbé and Trolard, which are large cortical veins but much smaller than the sinuses, responded similarly to treatment. The straight sinus and the SSS expanded more from endovascular treatment. The difference between the cortical veins and the venous sinuses was statistically significant for patients treated with papaverine and/or combined therapies ( $p=0.04$, according to analysis of variance), but not for those treated with angioplasty alone $(\mathrm{p}=0.38)$.

\section{Possible Cumulative Effect of Papaverine}

This was examined by measuring the diameter of veins in patients receiving papaverine infusion through the carotid circulation bilaterally in the same session. The venous diameters increased further with the second treatment (Fig. 3), although the differences were not statistically significant $(\mathrm{p}=0.12)$.

\section{Correlation Between Cerebral Circulation Time and Change in Venous Diameters With Treatment}

The cerebral circulation time has previously been measured in a group of patients receiving papaverine. ${ }^{28}$ Using similar methods of measurement, we found that the mean cerebral circulation time before administration of papaverine was $5.9 \pm 1.2$ seconds, and that the mean cerebral circulation time after delivery of papaverine was $3.8 \pm 0.8$ seconds. A good correlation was found between the cerebral circulation time and the change in venous diameters. That is, as the veins dilated due to the treatment, an associated decrease in the circulation time was observed $(r=$ -0.57 , Fig. 4).

\section{Correlation Between Change in Venous and Arterial Diameters With Treatment}

The increase in arterial diameter after infusion of papaverine ranged from 3.3 to $74.4 \%$, with a mean of $27.4 \% .{ }^{29}$ Arterial diameter changes were correlated with the change in venous diameters. The overall pattern was that veins behaved similarly to large arteries after treatment. A moderate correlation was found between the behavior of large arteries and veins $(r=0.54$, Pearson correlation coefficient); as the large arteries dilated with treatment, the veins tended to dilate as well. A weak correlation was found between the effect of treatment on medium and small arteries and the effect of treatment on the veins (medium arteries compared with veins, $r=0.03$;

\section{TABLE 1}

Percentage change in vessel diameter in 26 patients who underwent treatment for vasospasm after $S A H^{*}$

\begin{tabular}{lccc}
\hline \hline & \multicolumn{3}{c}{ Treatment } \\
\cline { 2 - 4 } Vein & Papaverine & Comb & Angioplasty \\
\hline Labbé & 7.1 & 8.0 & 11.6 \\
Trolard & 13.0 & -0.7 & -1.0 \\
straight sinus & 18.0 & 3.2 & -8.4 \\
SSS & 6.2 & 8.9 & -1.9 \\
\hline
\end{tabular}

$*$ Comb $=$ combined therapy consisting of papaverine and angioplasty. small arteries compared with veins, $r=-0.15$ ). As these smaller arteries dilated, the veins showed no consistent change.

\section{Correlation Between Initial ICP and Change in Venous Diameters With Treatment}

When initial ICP measurements were less than $15 \mathrm{~mm}$ $\mathrm{Hg}$ before treatment, the veins showed a greater tendency to dilate than when the initial ICP measurements were higher than $15 \mathrm{~mm} \mathrm{Hg}$. This pattern approached statistical significance $(\mathrm{p}=0.07$, $\mathrm{t}$-test). The ICP increased significantly after therapy with papaverine alone and when the agent was combined with angioplasty. The mean pretreatment ICP in patients receiving papaverine alone was 11 $\mathrm{mm} \mathrm{Hg}$ and reached a mean maximum of $21 \mathrm{~mm} \mathrm{Hg}(\mathrm{p}<$ 0.0001 , two-tailed paired t-test). The mean pretreatment ICP in patients treated with combined papaverine and angioplasty was $15 \mathrm{~mm} \mathrm{Hg}$ and reached a mean maximum ICP of $29 \mathrm{~mm} \mathrm{Hg}$ ( $p=0.025$, two-tailed paired t-test). The mean pretreatment ICP in patients who underwent angioplasty alone was $13 \mathrm{~mm} \mathrm{Hg}$, and a mean maximum ICP of $17 \mathrm{~mm} \mathrm{Hg}$ was reached (Fig. 5), which is not significant $(\mathrm{p}=0.21$, two-tailed paired $\mathrm{t}$-test). There was no apparent statistical correlation between the percentage change in venous diameters with treatment and the change in ICP. Similarly, there was no statistical significance in the correlation between initial ICP measurements and the change in ICP with treatment $(\mathrm{p}=0.39)$.

\section{Hunt and Hess Grades}

There was a tendency for patients with Hunt and Hess Grade I to have greater venous diameter changes with treatment (mean $22.5 \%$ increase) than patients with Grades II to IV (1.3-7.4\% increase). This pattern was statistically significant $(\mathrm{p}=0.03$, Fig. 6 left $)$.

\section{Fisher Grades}

There was no statistically significant relationship between Fisher grades on computed tomography scans and the change in venous diameters with treatment $(\mathrm{p}=0.39$, Fig. 6 right).

\section{Discussion}

The physiology of the cerebral venous system has long been neglected, due to preoccupation with arterial blood supply and circulation of CSF. In the latter half of the twentieth century, when angiography largely replaced dissection, extensive radiological descriptions of cerebral venous anatomy appeared; $22,33,35$ however, they dealt mostly with topographical landmarks, pathological displacements caused by masses, and anatomical variations. Changes in the diameter of the cerebral veins and dural sinuses were unexpected because, to our knowledge, the effects of endovascular treatment on the intracranial venous system have not been described. Multiple arteriograms of patients with SAH required side-by-side comparison of examinations to detect differences. This resulted in the observation that the veins and dural sinuses were dynamic and that there were variations in diameters between studies and interventions. This challenged 

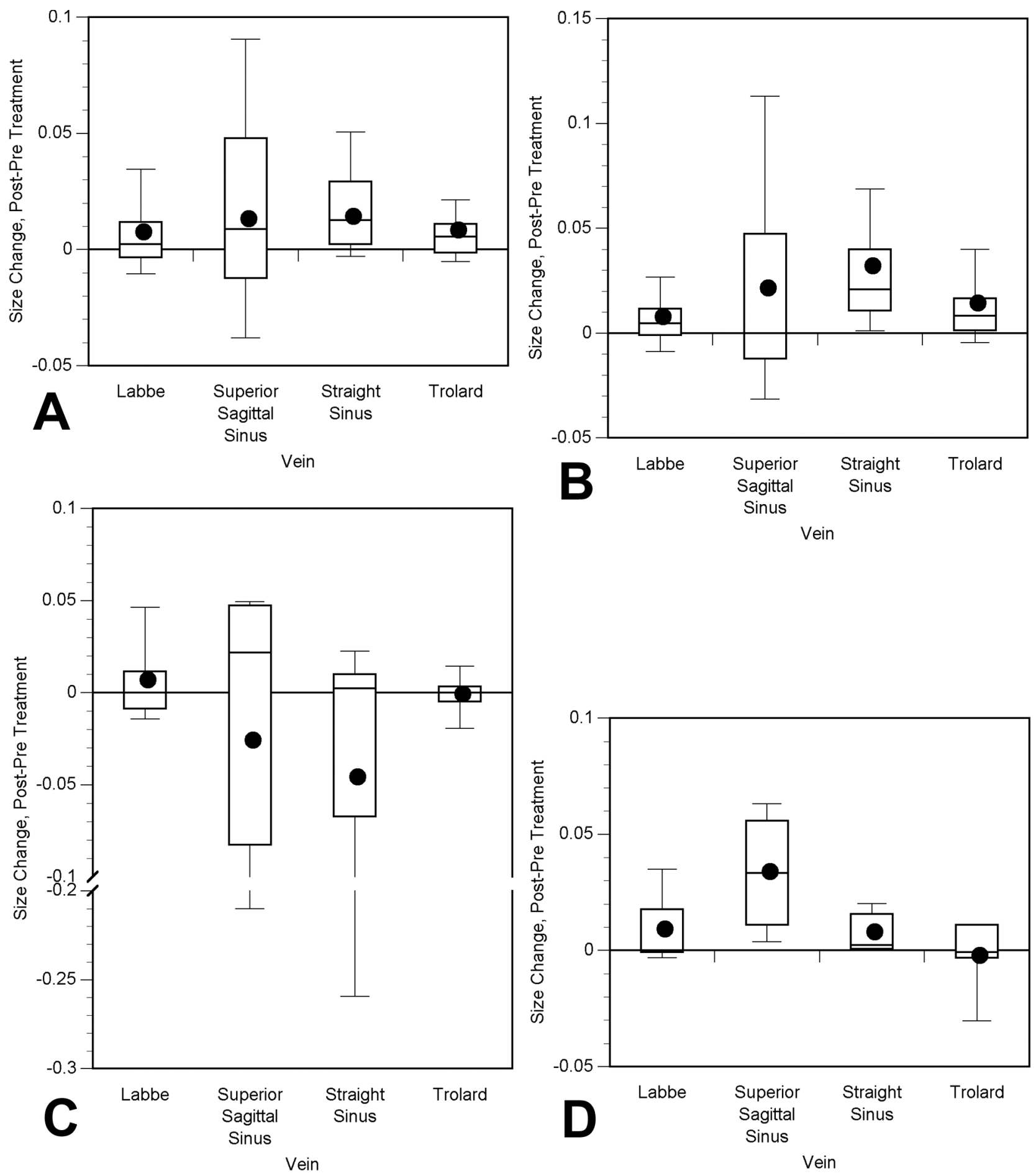

FIG. 2. Quartile plots showing the change in relative venous diameter corrected for magnification in the individual veins with all types of treatment. See Fig. 1 legend for explanation of the plot components. A: All treatments (papaverine, angioplasty, and combined therapies). B: Papaverine alone. C: Angioplasty alone. D: Combined papaverine and angioplasty.

the previous assumption that the veins and dural sinuses were static, which of course was incorrect; it had long been observed that the cerebral veins and dural sinuses decreased in size as arteriovenous malformations were resected, reflecting decreased flow. The fact that the veins and dural sinuses would increase or decrease in diameter as the CBF changed should not have been surprising. Most of the easily obtainable measures of flow are angiographic and indirect; the venous diameter changes offer another indirect measure of changes in flow. Because ve- 


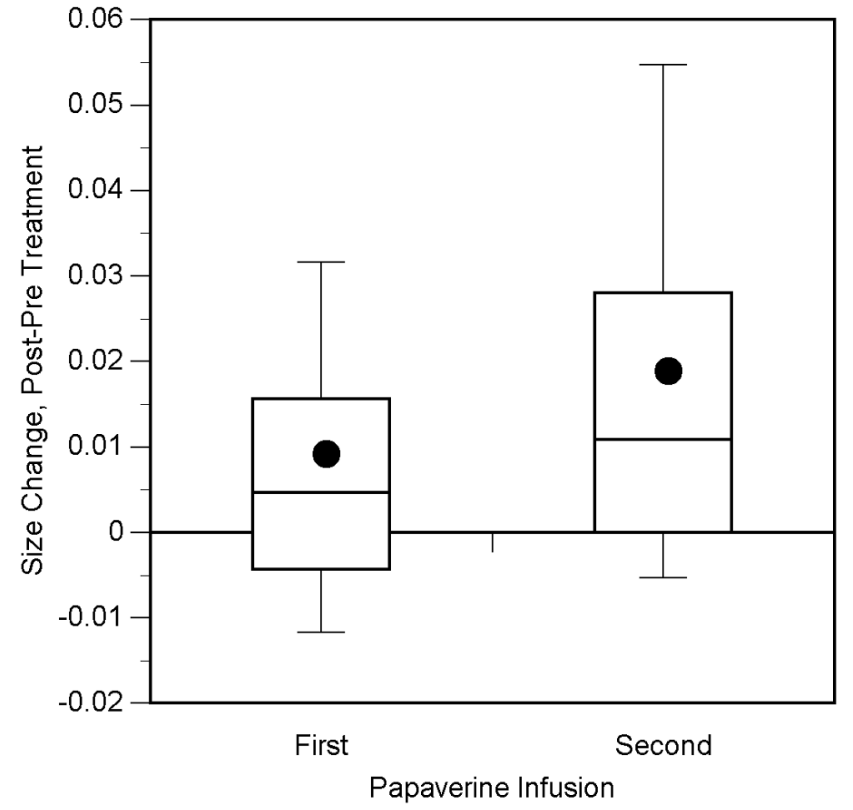

FIG. 3. Quartile plot showing change in venous diameters in patients receiving bilateral papaverine infusions in the same session. See Fig. 1 legend for explanation of the plot components.

nous blood accounts for $60 \%$ of the intracranial blood volume, ${ }^{39}$ changes in the intracranial venous system may explain some changes in cerebral hemodynamics.

Venous diameters increased after endovascular treatment. This was statistically significant after papaverine and combined papaverine and angioplasty therapy, but not after angioplasty alone. It may have been expected that the combined papaverine and angioplasty group would have larger venous diameters than the other groups. However, these patients showed a level of change between that of the group receiving papaverine alone and the group receiving angioplasty alone, but closer to the changes in the angioplasty-only group. That this pattern was not statistically significant was most likely due to the small population size.

There were considerable differences in the change in venous diameter, depending on the size of the vein. The veins of Labbé and Trolard, which are large cortical veins, responded similarly to treatment. The straight sinus and the SSS, which were much larger, responded more consistently to treatment. The changes in venous sinus diameters were greater with the second treatment than with the first in patients receiving papaverine infusion bilaterally through the carotid circulation during the same session. Although the difference was not statistically significant, a possible cumulative effect of papaverine is suggested. There are four possible explanations for increased venous diameters after endovascular treatment: increased CBF, increased CBV, increased ICP, or a direct vasodilatory effect of papaverine.

We observed a good correlation between the percentage change of cerebral venous diameters with papaverine treatment and the shortening of the angiographic cerebral circulation time. This observation was of interest because the mean cerebral circulation time is related to CBF. ${ }^{9}$ If papaverine causes consistent changes in cerebral circula- tion time and one assumes that the CBV increases as a result of papaverine infusion, then a decrease in cerebral circulation time and correspondingly dilated cerebral veins could indicate an increase in CBF. Other data also indicate that the cerebral circulation time does not significantly decrease after angioplasty alone (CJ Moran, DT Cross III, JM Milburn, unpublished data). Therefore, it can be suggested that papaverine and not angioplasty causes significantly increased CBF.

A moderate correlation was found between the increase in venous diameters with treatment and that of larger arteries; as the large arteries were dilated with treatment, the veins tended to dilate as well. This could be due to increased blood flow in arteries, leading to distention of the draining veins. The cerebral circulation differs from circulation through other organs in that it occurs within a rigid structure that has an intrinsic pressure (the ICP), which is normally less than $15 \mathrm{~mm} \mathrm{Hg} .^{41}$

A correlation between initial ICP measurements and a change in venous diameters with treatment was found. With ICP measurements less than $15 \mathrm{~mm} \mathrm{Hg}$ before treatment, the veins tended to dilate more than when the initial ICP measurements were higher than $15 \mathrm{~mm} \mathrm{Hg}$, and this increase approached statistical significance. Similarly, patients classified in Hunt and Hess Grade I had more venous dilation with treatment than did patients in higher grades. These patterns may be explained by adequate autoregulatory mechanisms, with normal ICP measurements and lower Hunt and Hess grades. This may allow greater venous dilation under these circumstances than with abnormal ICP measurements and higher Hunt and Hess grades.

It was interesting to note that the venous diameters on presentation tended to be smaller than the pretreatment diameters. This finding complements a study by Milburn,

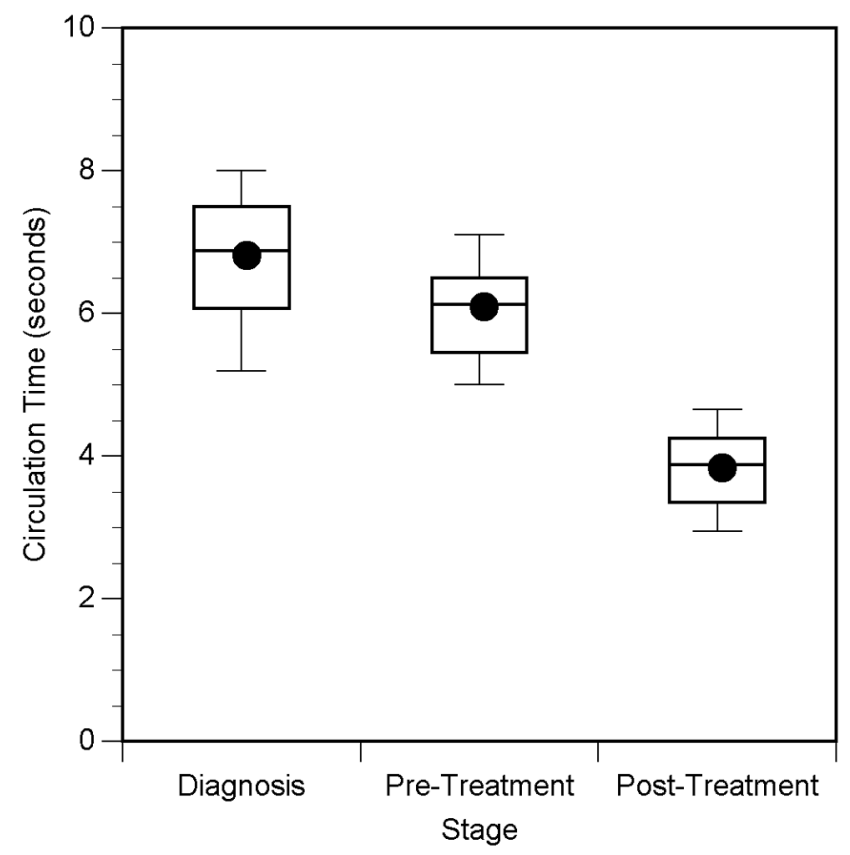

FIG. 4. Quartile plot showing the mean cerebral circulation time changes at diagnosis, pretreatment, and posttreatment. See Fig. 1 legend for explanation of the plot components. 


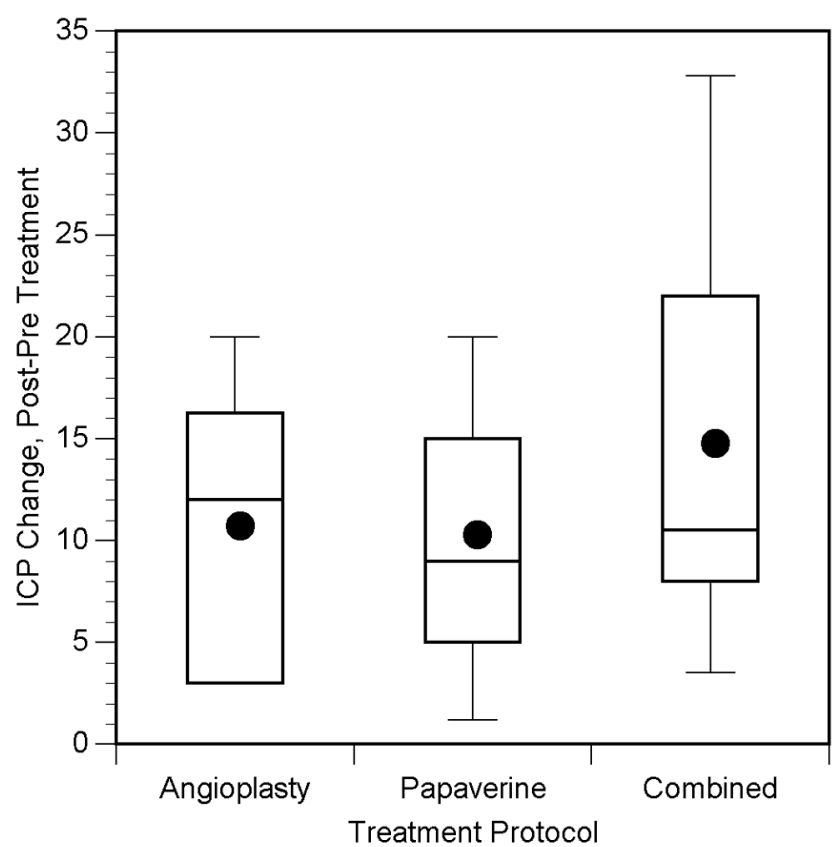

FIG. 5. Quartile plot showing the ICP change with each treatment modality. See Fig. 1 legend for explanation of the plot components. For angioplasty, the 75th and 90th percentiles have the same value due to small sample size.

et al. ${ }^{28}$ who found a somewhat prolonged angiographic circulation time (which we are calling cerebral circulation time) before treatment in many patients with SAH. This seemed to occur before the development of increased ICP. Later, with the development of clinical vasospasm, ICP is presumably higher and veins dilate due to increased venous pressure.

A rise in ICP can increase pressure in cerebral veins. ${ }^{10}$ It may be asked whether increased venous pressure causes increased ICP, or vice versa. Shulman and Ransohoff ${ }^{37}$ found elevated SSS pressure in infants with hydrocephalus, and when the elevated ICP was lowered by letting some CSF escape, the SSS pressure fell. These authors postulated that elevated CSF pressure causes partial collapse of the dural sinuses at or near the point of venous outflow from the skull.

Animal models ${ }^{20,25,30,34}$ and human studies ${ }^{27}$ have been used to evaluate the changes in ICP induced by papaverine infusion. The resultant significant increase in ICP was thought to be attributable to the agent's arterial vasodilatory action, ${ }^{25,30}$ but this increase still has not been completely explained.

Some increases in ICP were noticed after endovascular treatment in our study. This was statistically significant for the papaverine and combined papaverine and angioplasty groups but not for the group undergoing angioplasty alone. The ICP was near the normal physiological level in patients treated with angioplasty alone. The mean increase in ICP was slightly greater after combined papaverine and angioplasty treatment than with either mode of therapy alone.

The CBV has been thought to play an important role in the relationship between CBF and ICP. In certain clinical situations (such as head injuries) in which there is in- creased ICP, it has been suggested that intracranial blood volume is of greater importance than cerebral edema in producing acute brain swelling. ${ }^{21}$ Early animal experiments ${ }^{7,8,42}$ suggest that autoregulation in the brain is accomplished by changes in the diameter and therefore in the volume of the pial resistance vessels.

Many authors believe that vascular events leading to increased CBV are the main cause of increased ICP. ${ }^{41} \mathrm{Be}$ cause $\mathrm{CBV}$ is restricted by the cranium, most volume compensatory changes occur as a result of changes in the intracranial CSF and blood volumes. ${ }^{39}$ To maintain cerebral perfusion and blood flow to the tissues, further vasodilation is needed, although this raises ICP further, leading to a stepwise elevation of pressure..$^{41}$

It is known that large changes in blood volume can greatly stress the compensatory mechanisms required to maintain normal pressure, because the capacity of the resistance vessels to change will be exhausted. ${ }^{39}$ Because venous blood accounts for a larger part of the intracranial blood volume than arterial blood, we thought this could be an important factor in stressing the compensatory mechanisms to maintain ICP; thus, assessment of the intracranial venous system would contribute to a greater understanding of cerebral hemodynamics, providing further insight into treatment strategies in patients with vasospasm. Unexpectedly, however, our study showed no direct statistical correlation between venous enlargement and the increase in ICP with treatment.

It may be argued that combined capillary, arteriolar, arterial, and venous enlargement may contribute to increased CBV during treatment. However, it is also noteworthy that there was no statistical correlation between the change in arterial diameter with treatment and the increase in ICP. ${ }^{3}$ This may be explained in part by the fact that we continuously monitor ICP in patients receiving endovascular therapy at our institution, and the rate of pa-

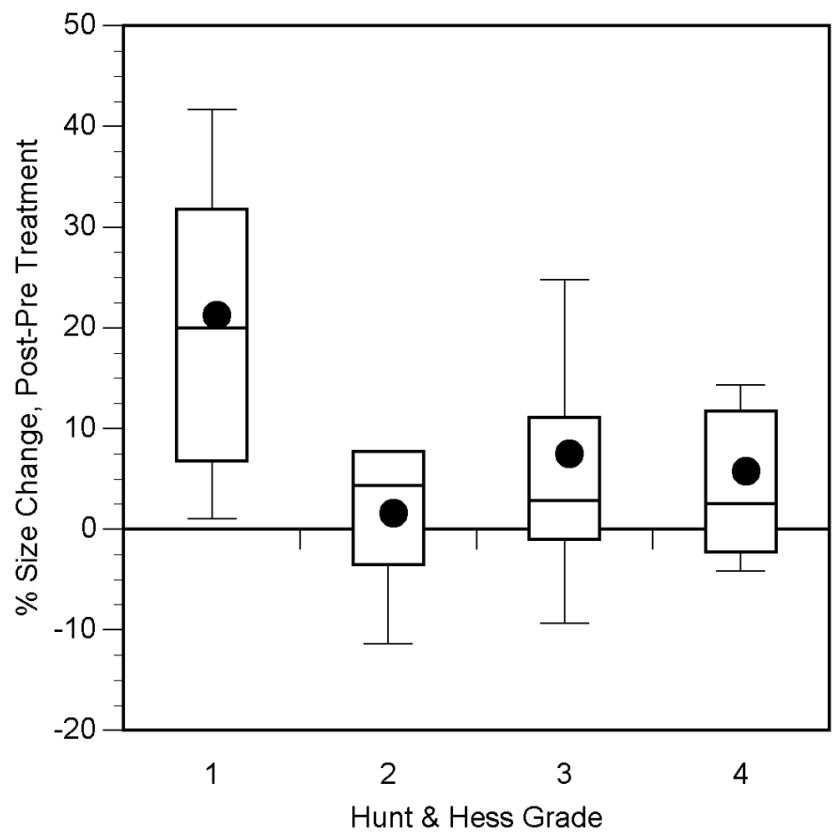

FIG. 6. Quartile plots showing the venous diameter changes with different Hunt and Hess grades (left) and Fisher grades (right). See Fig. 1 legend for explanation of the plot components. 
paverine infusion is adjusted accordingly to keep the CPP (calculated as mean arterial pressure - ICP) within the normal autoregulatory range of more than $60 \mathrm{~mm} \mathrm{Hg}$. Therefore, ICP is not allowed to reach high values. Furthermore, a delay of 10 to 15 minutes occurs between recording ICP and performing angiography in patients with pathologically elevated ICP, and this continues until their CPP returns to above $60 \mathrm{~mm} \mathrm{Hg}$. Thus, veins were not measured during the peak increase in ICP.

Finally, an alternative explanation for increased venous diameters after papaverine administration is that there is a direct effect on the venous wall. The cerebral veins have smooth muscle in the walls, and it would seem reasonable to observe dilation after papaverine administration, although we could not find published documentation of this. The venous sinuses are considered passive vessels consisting of endothelium-lined collagen walls. A direct vasodilatory effect should not occur if the action of papaverine has been correctly explained.

\section{Conclusions}

Endovascular treatment produces measurable increases in intracranial venous diameters. This increase does not correlate, however, with changes in ICP.

\section{References}

1. Brothers MF, Holgate RC: Intracranial angioplasty for treatment of vasospasm after subarachnoid hemorrhage: technique and modifications to improve branch access. AJNR Am J Neuroradiol 11:239-247, 1990

2. Clouston JE, Numaguchi Y, Zoarski GH, Aldrich EF, Simard JM, Zitnay KM: Intraarterial papaverine infusion for cerebral vasospasm after subarachnoid hemorrhage. AJNR Am J Neuroradiol 16:27-38, 1995

3. Cross DT III, Moran CJ, Angtuaco EE, Milburn JM, Diringer MN, Dacey RG Jr: Intracranial pressure monitoring during intraarterial papaverine infusion for cerebral vasospasm. AJNR Am J Neuroradiol 19:1319-1323, 1998

4. Fessler RD, Diaz FG: The management of cerebral perfusion pressure and intracranial pressure after severe head injury. Ann Emerg Med 22:998-1003, 1993

5. Findlay JM, Macdonald RL, Weir BKA: Current concepts of pathophysiology and management of cerebral vasospasm following aneurysmal subarachnoid hemorrhage. Cerebrovasc Brain Metab Rev 3:336-361, 1991

6. Fisher CM, Kistler JP, Davis JM: Relation of cerebral vasospasm to subarachnoid hemorrhage visualized by computerized tomographic scanning. Neurosurgery 6:1-9, 1980

7. Fog M: The relationship between blood pressure and the tonic regulation of the pial arteries. J Neurol Psychiatry 1:187-197, 1938

8. Forbes HS: The cerebral circulation. I. Observation and measurement of pial vessels. Arch Neurol Psychiatry 19: 751-761, 1928

9. Gado M, Eichling J, Grubb R, Phelps M, Raichle M, TerPogossian MM: Appraisal of the angiographic circulation time as an index of cerebral blood flow. Radiology 115:107-112, 1975

10. Gilroy J: Cerebral blood flow, in Rumbaugh CL, Wang AM, Tsai FY (eds): Cerebrovascular Disease: Imaging and Interventional Treatment Options. New York: Igaku-Shoin Medical Publishers, Inc, 1995, pp 23-32

11. Grubb RL Jr, Raichle ME, Eichling JO, Gado MH: Effects of subarachnoid hemorrhage on cerebral blood volume, blood flow, and oxygen utilization in humans. J Neurosurg 46: 446-453, 1977

12. Higashida RT, Halbach VV, Cahan LD, Brant-Zawadzki M, Barnwell S, Dowd C, et al: Transluminal angioplasty for treatment of intracranial arterial vasospasm. J Neurosurg 71: 648-653, 1989

13. Higashida RT, Halbach VV, Dowd CF, Dormandy B, Bell J, Hieshima GB: Intravascular balloon dilatation therapy for intracranial arterial vasospasm: patient selection, technique, and clinical results. Neurosurg Rev 15:89-95, 1992

14. Hunt WE, Hess RM: Surgical risk as related to time of intervention in the repair of intracranial aneurysms. J Neurosurg 28:14-20, 1968

15. Kaku Y, Yonekawa Y, Tsukahara T, Kazekawa K: Superselective intra-arterial infusion of papaverine for the treatment of cerebral vasospasm after subarachnoid hemorrhage. J Neurosurg 77:842-847, 1992

16. Kassell NF, Helm G, Simmons N, Phillips CD, Cail WS: Treatment of cerebral vasospasm with intra-arterial papaverine. J Neurosurg 77:848-852, 1992

17. Kassell NF, Sasaki T, Colohan AR, Nazar G: Cerebral vasospasm following aneurysmal subarachnoid hemorrhage. Stroke 16:562-572, 1985

18. Kassell NF, Torner JC, Haley EC Jr, Jane JA, Adams HP, Kongable GL: The International Cooperative Study on the Timing of Aneurysm Surgery. Part 1: overall management results. J Neurosurg 73:18-36, 1990

19. Kobayashi H, Ide H, Aradachi H, Arai Y, Handa Y, Kubota T: Histological studies of intracranial vessels in primates following transluminal angioplasty for vasospasm. J Neurosurg 78: 481-486, 1993

20. Kuwayama A, Zervas NT, Shintani A, Pickren KS: Papaverine hydrochloride and experimental hemorrhagic cerebral arterial spasm. Stroke 3:27-33, 1972

21. Langfitt TW, Tannanbaum HM, Kassell NF: The etiology of acute brain swelling following experimental head injury. J Neurosurg 24:47-56, 1966

22. Lasjaunias $P$, Berenstein A: Surgical Neuroangiography. New York: Springer, 1990, Vol 3, pp 68-87, 223-296

23. Le Roux PD, Newell DW, Eskridge J, Mayberg MR, Winn HR: Severe symptomatic vasospasm: the role of immediate postoperative angioplasty. J Neurosurg 80:224-229, 1994

24. Livingston K, Guterman LR, Hopkins LN: Intraarterial papaverine as an adjunct to transluminal angioplasty for vasospasm induced by subarachnoid hemorrhage. AJNR Am J Neuroradiol 14:346-347, 1993

25. Malkinson TJ, Cooper KE, Veale WL: Induced changes in intracranial pressure in anesthetized rat and rabbit. Brain Res Bull 15:321-328, 1985

26. Marks MP, Steinberg GK, Lane B: Intraarterial papaverine for the treatment of vasospasm. AJNR Am J Neuroradiol 14: 822-826, 1993

27. McAuliffe W, Townsend M, Eskridge JM, Newell DW, Grady MS, Winn HR: Intracranial pressure changes induced during papaverine infusion for treatment of vasospasm. J Neurosurg 83:430-434, 1995

28. Milburn JM, Moran CJ, Cross DT III, Diringer MN, Pilgram TK, Dacey RG Jr: The effect of intra-arterial papaverine on cerebral circulation time. AJNR Am J Neuroradiol 18: 1081-1085, 1997

29. Milburn JM, Moran CJ, Cross DT III, Diringer MN, Pilgram TK, Dacey RG Jr: Increase in diameters of vasospastic intracranial arteries by intraarterial papaverine administration. J Neurosurg 88:38-42, 1998

30. Murata S, Kikkawa K, Nagao T: Cerebral vasodilating and spasmolytic actions of a new Ca-antagonist, clentiazem (TA3090), in anesthetized animals. J Cardiovasc Pharmacol 19: 790-797, 1992

31. Nakagomi T, Kassell NF, Hongo K, Sasaki T: Pharmacological 


\section{Effect of papaverine and/or angioplasty on veins after SAH}

reversibility of experimental cerebral vasospasm. Neurosurgery 27:582-586, 1990

32. Newell DW, Eskridge JM, Mayberg MR, Grady MS, Winn HR: Angioplasty for the treatment of symptomatic vasospasm following subarachnoid hemorrhage. J Neurosurg 71:654-660, 1989

33. Newton TH, Potts DG: Veins, in Radiology of the Skull and Brain. Angiography. St. Louis: CV Mosby, Vol 2, 1974, pp 1851-2254

34. Pickering GW: Observations on the mechanism of headache produced by histamine. Clin Sci 1:77-101, 1993

35. Salamon G, Huang YP: Basal cerebral vein, in Radiologic Anatomy of the Brain. New York: Springer-Verlag, 1976, pp 127-174

36. Selman WR, Ratcheson RA: Intracranial aneurysms, in Bradley WG, Daroff RB, Fenichel GM, et al (eds): Neurology in Clinical Practice. Boston: Butterworth-Heinemann, Vol 2, 1996, pp 1048-1062

37. Shulman K, Ransohoff J: Sagittal sinus venous pressure in hydrocephalus. J Neurosurg 23:169-173, 1965

38. Tanabe Y, Sakata K, Yamada H, Ito T, Takada M: Cerebral vasospasm and ultrastructural changes in cerebral arterial wall. An experimental study. J Neurosurg 49:229-238, 1978

39. van Dellen JR: Trauma of the nervous system. A. Craniocerebral trauma, in Bradley WG, Daroff RB, Fenichel GM, et al (eds): Neurology in Clinical Practice. Boston: ButterworthHeinemann, Vol 2, 1996, pp 941-970
40. Vorkapic P, Bevan RD, Bevan JA: Longitudinal time course of reversible and irreversible components of chronic cerebrovasospasm of the rabbit basilar artery. J Neurosurg 74:951-955, 1991

41. Wald SL: Disorders of cerebrospinal fluid circulation and brain edema, in Bradley WG, Daroff RB, Fenichel GM, et al (eds): Neurology in Clinical Practice. Boston: ButterworthHeinemann, Vol 2, 1996, pp 1432-1433

42. Wolff HG, Forbes HS: The cerebral circulation. Observations of the pial circulation during changes in intracranial pressure. Arch Neurol Psychiatry 20:1035-1047, 1928

43. Yamamoto Y, Smith RR, Bernanke DH: Mechanism of action of balloon angioplasty in cerebral vasospasm. Neurosurgery 30: $1-6,1992$

44. Zubkov YN, Nikiforov BM, Shustin VA: Balloon catheter technique for dilatation of constricted cerebral arteries after aneurysmal SAH. Acta Neurochir (Wien) 70:65-79, 1984

Manuscript received July 10, 2006.

Accepted in final form August 18, 2006.

Address reprint requests to: Christopher J. Moran, M.D., Washington University School of Medicine, 510 South Kingshighway Boulevard, St. Louis, Missouri 63110-1076. email: MoranC @wustl.edu 